\title{
Modal Analysis of Hipped Hypar Shell by Using ANSYS
}

\author{
Umale Shubhangi Tejrao ${ }^{1,}$ Dr. Shinde Sangeeta B ${ }^{2}$ \\ ${ }^{1}$ (Department of Civil Engineering, BAMU University, Aurangabad \\ ${ }_{2}^{2}$ (Department of Civil Engineering, BAMU University, Aurangabad
}

\begin{abstract}
In the present work, Finite element analysis is done by using FEM based software ANSYS (version 15) on hipped hypar shell with uniform pressure. The results obtained for two different material properties of steel and aluminium are compared by using modal static structural analysis. The analysis result of deformation upto eight mode with varryig frequency obtained by ANSYS are compared for two material properties. And these results are compared with regression analysis for accuracy.
\end{abstract}

Keywords: ANSYS (V15), Hipped Hypar Shell, Modal analysis, Regression analysis

\section{Introduction}

The hipped hypar shells are widely used in many engineering application like roof of building, aircraft industry . Shells are called as a thin shells when the radius-to-thickness ratio of 200. Thin shells provide an advantageous low consumption of material. The low consumption of material in shell structures follows the curvature in spatial form from the unique character of the shell. This unique character is responsible for the profound that shell structures are very efficient in carrying loads acting perpendicular to their surface by membrane action, a general state of stress which consists of in-plane normal and shear stress resultants only, whereas other structural forms carry the applied load mostly by bending action which is the least efficient load carrying method. This membrane action results in in-plane membrane stresses which can be absorbed by only a small thickness of the shell. As a consequence shell structures can be very thin

In the present paper hyperbolic paraboloid ( Hipped Hypar) shell is considered. A general solution is obtained by finite element based analysis software. In modal analysis the results obtained in form of deformation and frequency.

\section{About The Software}

ANSYS software uses usual FEM equilibrium equations for analysing of hyperbolic paraboloid shells problems. ANSYS is modeling and analysis software which helps in the modeling and analysis of required models, a FEM tool. It is used to analyse complex problems in mechanical structures, thermal processes, electrical fields, computational fluid dynamics. ANSYS provides a rich graphics environment which is used to display results of analysis that re performed.

\section{Methodology}

A hipped hyper shells with uniform pressure problem is considered. Two different material are compared that is steel and aluminium by using static and modal analysis. These shell modeled and analysed in ANSYS software. Pressure of 400 Pascal applied on all faces of shell in both material.In this paper the effect of these material are studied and compared using the results obtained in the form of deformation and frequency by ANSYS. And these results of different material are compared with regression analysis.

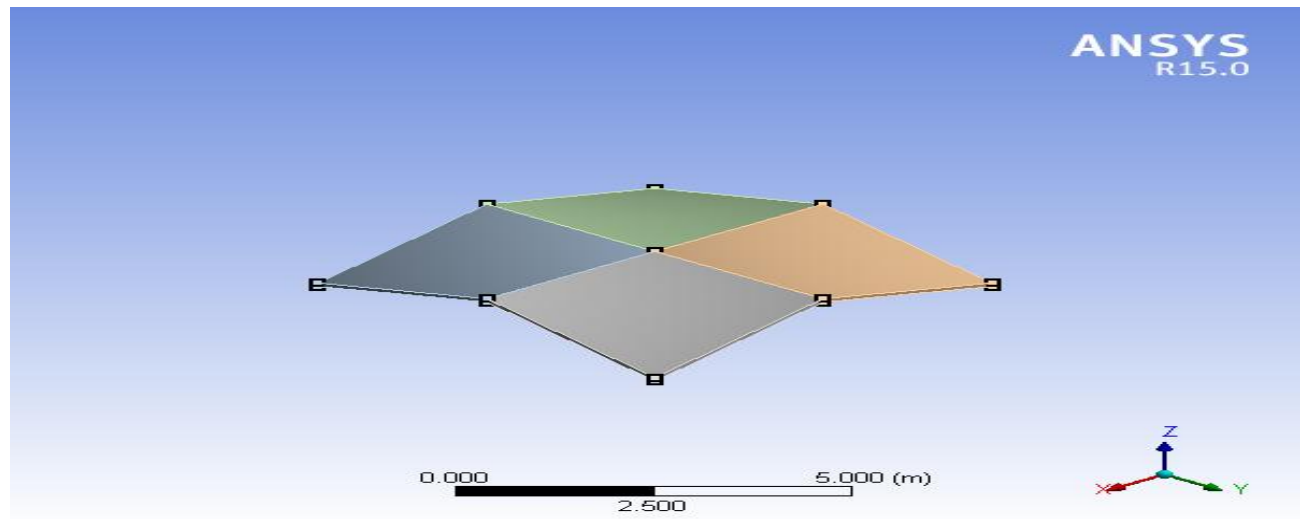

Fig. 1. Model showing shell is simply supported on four edges (For both material properties) 
TABLE I. MATERIAL PROPERTIES FOR STEEL AND ALUMINIUM

\begin{tabular}{|l|l|l|}
\hline \multicolumn{1}{|c|}{ Material Properties } & \multicolumn{1}{|c|}{ Structural Steel } & \multicolumn{1}{c|}{ Aluminium } \\
\hline Density & $769.81 \mathrm{KN} / \mathrm{m}^{3}$ & $265.75 \mathrm{KN} / \mathrm{m}^{3}$ \\
\hline Compressive Ultimate Strength & $0 \mathrm{KN} / \mathrm{m}^{2}$ & $0 \mathrm{KN} / \mathrm{m}^{2}$ \\
\hline Compressive Yield Strength & $250 \times 10^{3} \mathrm{KN} / \mathrm{m}^{2}$ & $240 \times 10^{3} \mathrm{KN} / \mathrm{m}^{2}$ \\
\hline Tensile Yield Strength & $250 \times 10^{3} \mathrm{KN} / \mathrm{m}^{2}$ & $240 \times 10^{3} \mathrm{KN} / \mathrm{m}^{2}$ \\
\hline Tensile Ultimate Strength & $460 \times 10^{3} \mathrm{KN} / \mathrm{m}^{2}$ & $290 \times 10^{3} \mathrm{KN} / \mathrm{m}^{2}$ \\
\hline Young's Modulus & $200 \times 10^{6} \mathrm{KN} / \mathrm{m}^{2}$ & $71 \times 10^{6} \mathrm{KN} / \mathrm{m}^{2}$ \\
\hline Poisson's Ratio & 0.3 & 0.33 \\
\hline Bulk Modulus & $166.7 \times 10^{6} \mathrm{KN} / \mathrm{m}^{2}$ & $69.60 \times 10^{6} \mathrm{KN} / \mathrm{m}^{2}$ \\
\hline Shear Modulus & $76.23 \times 10^{6} \mathrm{KN} / \mathrm{m}^{2}$ & $26.692 \times 10^{6} \mathrm{KN} / \mathrm{m}^{2}$ \\
\hline Thickness & $100 \mathrm{~mm}$ & $100 \mathrm{~mm}$ \\
\hline
\end{tabular}

TABLE II. MODEL GEOMETRY FOR SHELL

\begin{tabular}{|l|l|l|l|}
\hline Geometry parts & Steel & Aluminium \\
\hline Bounding Box & Length X & $6000 \mathrm{~mm}$ & $6000 \mathrm{~mm}$ \\
\cline { 2 - 4 } & Length Y & $6000 \mathrm{~mm}$ & $6000 \mathrm{~mm}$ \\
\cline { 2 - 4 } & Length Z & $1110.7 \mathrm{~mm}$ & $1110.7 \mathrm{~mm}$ \\
\hline \multirow{5}{*}{ Properties } & Volume & $3.7 \times 10^{9} \mathrm{~mm}^{3}$ & $3.0 \times 10^{9} \mathrm{~mm}^{3}$ \\
\cline { 2 - 4 } & Mass & $290.54 \mathrm{KN}$ & $100.63 \mathrm{KN}$ \\
\cline { 2 - 4 } & Centroid X & $2317 \mathrm{~mm}$ & $2317 \mathrm{~mm}$ \\
\cline { 2 - 4 } & Centroid Y & $2003.3 \mathrm{~mm}$ & $2003.3 \mathrm{~mm}$ \\
\cline { 2 - 4 } & Centroid Z & $2985.6 \mathrm{~mm}$ & $2985.6 \mathrm{~mm}$ \\
\cline { 2 - 4 } & Moment of Inertia Ip1 & $441 \mathrm{KN} \mathrm{m}^{2}$ & $153.66 \mathrm{KN} \mathrm{m}^{2}$ \\
\cline { 2 - 4 } & Moment of Inertia Ip2 & $112.7 \mathrm{KN} \mathrm{m} \mathrm{KN} \mathrm{m}^{2}$ & $402.48 \mathrm{KN}^{2}$ \\
\cline { 2 - 4 } & Moment of Inertia Ip3 & $554.68 \mathrm{KN} \mathrm{m}^{2}$ & $192.27 \mathrm{KN} \mathrm{m}^{2}$ \\
\hline Statistics & Nodes & 206608 & 206608 \\
\cline { 2 - 3 } & Elements & 42632 & 42632 \\
\hline
\end{tabular}

\section{Results}

In modal analysis the results calculated by ANSYS in the form of maximum deformation and frequency for hyperbolic paraboloid shell with uniform pressure 400 pascal.

TABLE III. FREQUENCY

\begin{tabular}{|c|c|c|c|c|}
\hline Mode & $\begin{array}{c}\text { Steel by using ANSYS } \\
(\mathrm{Hz})\end{array}$ & $\begin{array}{c}\text { Steel by using } \\
\text { Regression } \\
(\mathrm{Hz})\end{array}$ & $\begin{array}{c}\text { Aluminium by using } \\
\text { ANSYS } \\
(\mathrm{Hz})\end{array}$ & $\begin{array}{c}\text { Aluminium by using } \\
\text { Regression } \\
(\mathrm{Hz})\end{array}$ \\
\hline 1 & $1.24 \times 10^{-2}$ & 14.512 & $1.19 \times 10^{-2}$ & 14.71 \\
\hline 2 & 43.878 & 32.1808 & 44.256 & 32.63 \\
\hline 3 & 43.879 & 49.848 & 44.257 & 50.55 \\
\hline 4 & 70.211 & 67.516 & 71.173 & 68.47 \\
\hline 5 & 92.738 & 85.184 & 94.762 & 86.39 \\
\hline 6 & 117.98 & 102.65 & 119.93 & 104.31 \\
\hline 7 & 117.98 & 120.52 & 119.93 & 122.23 \\
\hline 8 & 124.12 & 138.18 & 125.2 & 140.159 \\
\hline
\end{tabular}

TABLE IV. MAXIMUM DEFORMATION

\begin{tabular}{|c|c|c|c|c|}
\hline Mode & $\begin{array}{c}\text { Steel by using ANSYS } \\
(\mathrm{mm})\end{array}$ & $\begin{array}{c}\text { Steel by using } \\
\text { Regression } \\
(\mathrm{mm})\end{array}$ & $\begin{array}{c}\text { Aluminium by using } \\
\text { ANSYS } \\
(\mathrm{mm})\end{array}$ & $\begin{array}{c}\text { Aluminium by using } \\
\text { Regression } \\
(\mathrm{mm})\end{array}$ \\
\hline 1 & 0.00018478 & 0.000204 & 0.0099285 & 0.0019 \\
\hline 2 & 0.00026572 & 0.000208 & 0.014225 & 0.0153 \\
\hline 3 & 0.00026571 & 0.000212 & 0.014224 & 0.0172 \\
\hline 4 & 0.00031729 & 0.000216 & 0.017028 & 0.0191 \\
\hline 5 & 0.00066547 & 0.00022 & 0.035815 & 0.021 \\
\hline 6 & 0.00055024 & 0.00024 & 0.025809 & 0.0229 \\
\hline 7 & 0.00055024 & 0.00028 & 0.025809 & 0.0248 \\
\hline 8 & 0.0003099 & 0.00032 & 0.016562 & 0.0267 \\
\hline
\end{tabular}




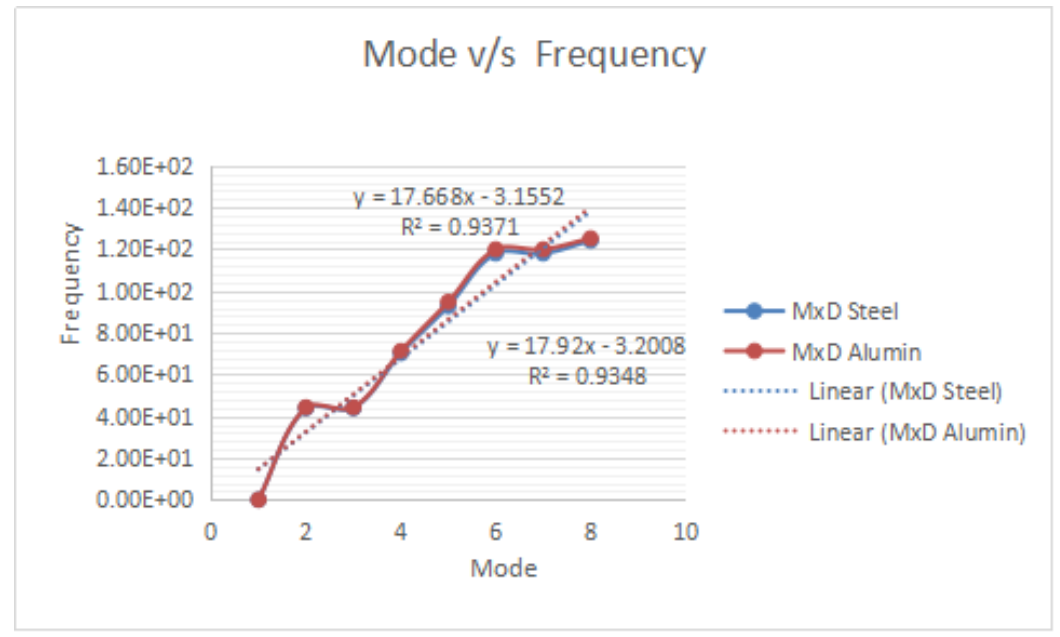

Fig. 2. Graph Mode v/s Frequency

This graph represents the variation of frequency of steel and aluminium hyperbolic paraboloid shell upto eighth mode using modal analysis. And the equation shown on graph using trendline equation is regression analysis. $y=17.668 x-3.1552 R^{2}=0.9371$ (for steel); $y=17.92 x-3.2008 R^{2}=0.9348$ (for aluminium)

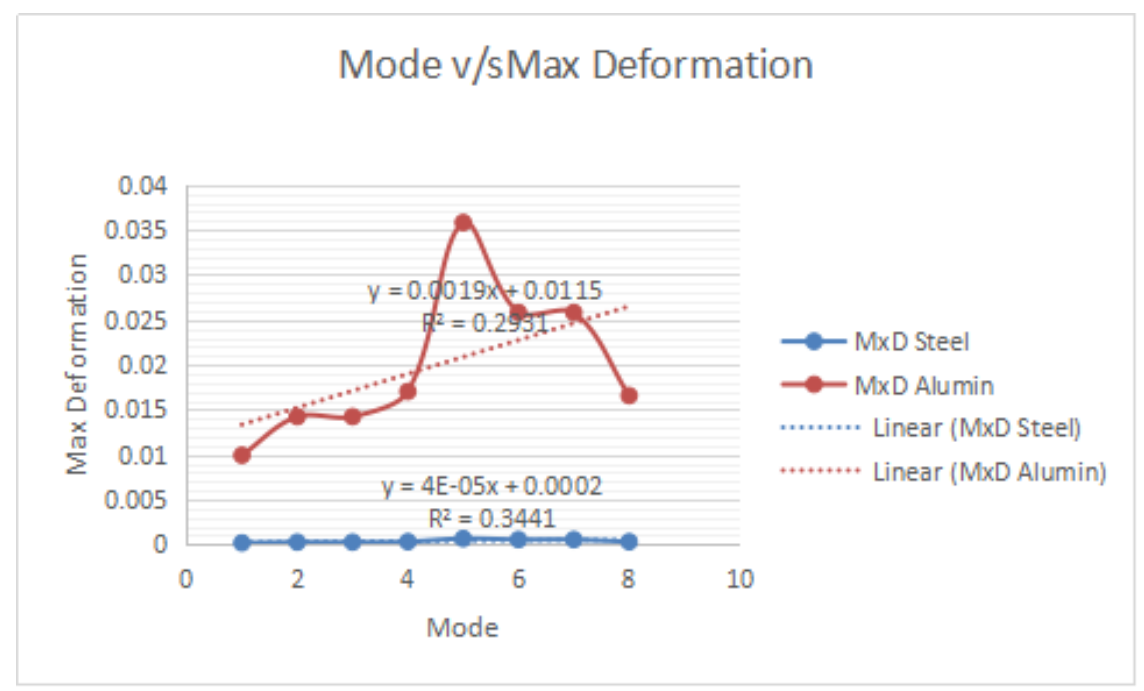

Fig. 3. Graph of Variation of Maximum deformation

This graph represents the variation of deformation of steel and aluminium hyperbolic paraboloid shell upto eighth mode using modal analysis. And the equation shown on graph using trendline equation is regression analysis.

$y=4 X 10^{-5} x+0.0002 R^{2}=0.3441$ (for steel); $y=0.0019 x+0.0115 R^{2}=0.2931$ (for aluminium)

From the graph we can see that there is sudden changes from fifth mode to sixth mode in deformation as well as in frequency, this happens due to loading and boundary condition as the shell is simply supported the maximum deformation and the frequency occurs at the edges of the shell in $\mathrm{x}$-direction.

\section{Conclusion}

In this study, The finite element analysis of modal analysis were performed for hyperbolic paraboloid shell problem for steel and aluminium material using ansys are concluded as follow:

1. The maximum deformation of steel shell is less than the aluminium shell by modal analysis and also by regression analysis. The value of regression analysis calculated on Graph.3. using trendline which gives very nearer value for steel material and aluminium as calculated value by ansys.

2. The frequency of steel shell is less than the aluminium shell by modal analysis and also by regression analysis. The value of regression analysis calculated on Graph.2. using trendline which gives nearer value for steel material and aluminium as calculated value by ansys.

3. From this analysis we can conclude that steel material is better than aluminium for design and analysis of hipped hyper shell. 


\section{References}

[1]. W. Flügge, "Stresses in Shells," Springer-Verlag, Berlin,1960. doi:10.1007/978-3-662-01028-0.

[2]. $\quad$ L. Gol'denveizer, "Theory of Elastic Thin Shells," Pergamon Press, Oxford, 1961.

[3]. Messina, "Free Vibrations of Multilayered DoublyCurved Shells Based on a Mixed Variational Approach and Global PiecewiseSmooth Functions," International Journal of Solids and Structures, Vol. 40, No. 12, 2003,pp.3069-3088.

[4]. Francesco Tornabene, Alessandro Ceruti "Free-Form Laminated Doubly-Curved Shells and Panels of Revolution Resting on Winkler-Pasternak Elastic Foundations: A 2-D GDQ Solution for Static and Free Vibration Analysis" World Journal of Mechanics, 2013, 3, 1-25.

[5]. J.B. Han and K. M. Liew, "Static Analysis of Mindlin Plates: The Differential Quadrature Element Method DQEM," Computer Methods in Applied Mechanics and Engineering,Vol. 177, No. 1-2, 1999, pp. 51-75 